\title{
Conhecimento tácito e raciocínio clínico em psiquiatria
}

\section{Tacit knowledge and clinical reasoning in psychiatry}

\author{
Claudio E. M. Banzato ${ }^{1}$, Rafaela T. Zorzanelli ${ }^{2}$
}

\section{Resumo}

Clínicos alternam constantemente o foco de sua atenção quando se deparam com um paciente que apresenta fenômenos psicopatológicos. Seguramente, não é possível determinar de antemão (ou seja, até que se passe algum tempo do processo de avaliação diagnóstica) onde reside o problema, se é necessário operar um zoom in e investigar o cérebro do paciente (ou os genes), ou operar um zoom out e prestar atenção especial a seu mundo relacional (ou social), ou, ainda, se devemos nos concentrar em sua própria experiência subjetiva. Em psiquiatria, lidamos com sujeitos corporais e suas ações, tal como descritas dentro de um contexto, não meramente com disfunções de partes do corpo. No entanto, se rejeitamos o reducionismo, isto é, a ideia de que há um nível explicativo único e fundamental para todos os transtornos mentais, e adotamos, em vez disso, um modelo multinível dentro de uma posição explanatória pluralista, permanecerá indeterminado se tais mudanças nos níveis explanatórios que ocorrem na prática clínica cotidiana podem ou não ser inteiramente codificadas ou, em outras palavras, em que medida essas mudanças se apoiam, inevitavelmente, em um conhecimento tácito. Se esse é o caso, não seria possível codificar o julgamento clínico em algoritmos, mesmo que muito sofisticados.

Palavras-chave: Modelos multinível; Pluralismo explanatório; Julgamento clínico

\begin{abstract}
Clinicians constantly shift the focus of their attention when seeing a patient who presents psychopathological phenomena. Arguably, it is not possible to tell in advance (that is, before quite a while in the diagnostic assessment process) where the problem lies, whether it is necessary to zoom in and look into the patient's brain (or genes), or if we have to zoom out and pay special attention to his/her relational (or social) world, or if we should concentrate on his/her own subjective experience. In psychiatry, we deal with embodied subjects and their actions under description and within context, not merely bodily dysfunctions. However, if we reject
\end{abstract}

Psicopatologia Fenomenológica Contemporânea, 2017;6(2):81-92 
reductionism, i.e., the very idea that there is a single fundamental level of explanation for all mental disorders, and adopt instead a multilevel model within a pluralist explanatory stance, it remains to be determined whether or not such changes of explanatory levels that take place in everyday clinical practice can be fully codified or, in other words, to which extent they inevitably rely on tacit knowledge. If that is the case, then no algorithm, however sophisticated, can fully capture clinical reasoning.

Keywords: Multilevel models; Explanatory pluralism; Clinical judgment

1 Departamento de Psicologia Médica e Psiquiatria, Faculdade de Ciências Médicas, Universidade Estadual de Campinas - UNICAMP - Campinas (SP), Brasil. E-mail: claudio@lexxa.com.br

${ }^{2}$ Instituto de Medicina Social, Universidade Estadual do Rio de Janeiro - UERJ - Rio de Janeiro (RJ), Brasil. E-mail: rtzorzanelli@gmail.com

Artigo baseado na conferência Tacit knowledge and clinical reasoning in psychiatry, ministrada por Claudio E. M. Banzato em 04/11/2016, no encontro INPP-2016, em São Paulo.

Recebido: 26/4/2017

Aceito: $24 / 8 / 2017$ 


\begin{abstract}
"We live in a world that places a high premium on standardization and objectivicty; sublety and complexity are imperiled in that world."
\end{abstract}

Nancy Andreasen, 1995

"The necessary knowledge is that of what to observe."

Edgar Alan Poe, 1992 [1841]

A psiquiatria contemporânea, no afã de sua incessante busca por fundamentos científicos em que a prática clínica possa se apoiar, precisa reconhecer duas fortes tendências que operam em seu interior: o fascínio exercido por um objetivismo ingênuo, preconceito que estipula que todos os fenômenos são mais bem conhecidos na medida em que são vistos de forma objetiva (isto é, da forma mais neutra e imparcial, como se fosse, para usar a expressão de Nagel, uma visão a partir de "nenhum lugar"), posição essa que pode degenerar numa espécie de "cegueira objetiva" (Nagel, 1986), e o encanto provocado por um reducionismo voraz, no qual certo recorte específico de poucas variáveis selecionadas - variáveis essas de um tipo apenas ou de um único plano, definido, a priori, como fundamental, e esse é o ponto crítico aqui -, mimetizando o formato de leis generalizáveis, gera explicações demasiadamente simples para fenômenos complexos. É importante frisar que não há nada de errado com a objetividade ou com o reducionismo, posto que constituem valorizados métodos de entendimento e explicação, que estão na base do próprio conhecimento científico como virtudes epistemológicas relevantes para sua produção (Zorzanelli, Dalgalarrondo \& Banzato, 2016). O que pretendemos destacar, neste artigo, é apenas o papel de "ideal de precisão" que o objetivismo ingênuo e o reducionismo voraz, sobretudo quando combinados - o que, aliás, não é raro - desempenham na psiquiatria, determinando, de antemão, o que deve contar como uma explicação legítima de todo e qualquer fenômeno psicopatológico.

Em psicopatologia, a regra é nos depararmos com fenômenos complexos, cujo significado só pode ser interpretado se levarmos em conta o conjunto da vida mental do indivíduo, de sua biografia e de suas circunstâncias. É sempre necessário examinar simultaneamente a parte e o

Psicopatologia Fenomenológica Contemporânea, 2017;6(2):81-92 
todo. Neste campo, não estamos diante de blocos discretos, de valência inequívoca e de caráter evidente. Pelo contrário, recortamos aspectos subjetivos e comportamentais de certa maneira, legada pela tradição, guiados por hipóteses construídas ao longo do encontro clínico. Berrios e Chen (1993) mostram que o reconhecimento de sintomas e o reconhecimento de doenças ou transtornos não são eventos independentes, mas, sim, interdependentes. O corolário disso é que a utilização de critérios diagnósticos explícitos baseados em sintomas não garante, em absoluto, a objetividade de um diagnóstico. Antecipando o argumento sobre a natureza, em larga medida, tácita do raciocínio clínico, sugerimos que, em virtude de seu treinamento prático (aprendizado ostensivo) e experiência profissional, um clínico competente reconhece e distingue padrões (pois opera o tempo todo separando e agrupando aspectos dos fenômenos) e, nesse processo, sua sensibilidade ${ }^{1}$ para captar aqueles detalhes que fazem a diferença é decisiva.

Uma breve nota sobre o reducionismo: como salientado acima, nada há de errado com a redução metodológica. O que nos parece problemático é a ideia (de forte apelo científico, com repercussões ainda mais evidentes na divulgação da ciência) de que conceitos de determinado plano ou nível explicativo seriam inteiramente redutíveis a outro plano ou nível explicativo, que seria mais básico ou fundamental. E, por conseguinte, a melhor explicação seria sempre aquela formulada nesse plano supostamente mais básico ou fundamental. A questão que nos interessa é o caráter apriorístico e absoluto imputado a essa primazia. O que predomina na psiquiatria atual, muito influenciada pelo desenvolvimento recente das neurociências, é a posição que concede à biologia, em geral, e ao cérebro, em particular, tal primazia explicativa. Miller e Keller (2000) resumem bem o que está em jogo nesse reducionismo ontológico, afirmando que "não é uma propriedade dos dados biológicos que eles sejam ‘subjacentes’ aos dados psicológicos.” Ora, não é necessário que entre a biologia e a psicologia exista uma relação de precedência ou de subordinação, ou, ainda, que explicações de um único tipo sejam consideradas mais fundamentais.

\footnotetext{
${ }^{1}$ Nesse caso, denominou-se sensibilidade clínica a capacidade de processar informações sobre a condição do indivíduo e de perceber quais variáveis predominam ou entram em jogo de forma mais determinante na composição de um quadro específico de adoecimento psicopatológico, naquele momento particular (levando em conta a história clínica pregressa), utilizando essa percepção global para a tomada de decisões.
}

Psicopatologia Fenomenológica Contemporânea, 2017;6(2):81-92 
Essa posição hierárquica entre esses níveis resulta mais do estilo de pensamento predominante (Fleck, 1979) e do coletivo de pensamento - ou seja, valores, ideias, percepções tacitamente acordadas, em torno dos quais se define o que é ciência ou não - do que dessa propriedade dos dados per se. A noção de que haveria um plano descritivo básico está intimamente ligada à ideia de uma cadeia causal, que poderia ser rastreada até o seu ponto de origem, o seu marco zero, por assim dizer. Nesta tradição e estilo de pensamento, observa-se a tendência de acoplar o reducionismo ontológico à preferência por explicações causais formuladas no vocabulário de um único plano. $\mathrm{O}$ marco da célebre descoberta de Bayle sobre a paralisia geral progressiva, estabelecendo, pela primeira vez em psiquiatria, o nexo causal entre o que se considerava uma entidade nosológica típica e uma lesão cerebral demonstrável, parece ecoar fortemente até hoje e realimentar com aparatos tecnológicos de acesso ao cérebro muito mais potentes que outrora, a esperança de uma nova descoberta da mesma ordem, no campo da psiquiatria atual.

Que isso ocorra tão frequentemente é um indicativo seguro do prestígio emprestado a uma determinada concepção de realidade. Lê-se, por exemplo, no documento programático do NIMH (2008) sobre o projeto Research Domain Criteria (RDoC), que "mental illnesses are now studied as brain disorders, specifically as disorders of brain circuits". O trecho ecoa, em linguagem renovada e com novo fôlego, aquela velha esperança novecentista de encontrar os determinantes e marcadores cerebrais dos transtornos mentais.

Contra a expectativa de um reducionismo implacável, vale a pena comentar, ainda que brevemente, o caso exemplar, analisado por Kenneth Schaffner (2008), do ilustre Caenorhabditis elegans, um nematoide transparente, de apenas $1 \mathrm{~mm}$ de comprimento, que possui um sistema nervoso com invariantes 302 neurônios e que tem os seus genes inteiramente sequenciados. Considerado o "sonho do reducionista", esse pequeno organismo tem dois padrões de alimentação distintos, um social e outro solitário (Schaffner, 2008). Os estudos sobre a determinação de tais padrões alimentares, no entanto, sugerem um cenário muito mais complexo do que supõe a posição reducionista. Tudo parece indicar que a relação entre genes, neurônios, circuitos e comportamento seja uma relação do tipo múltiplo-múltiplo (many-many relation), em que múltiplos genes afetam um único neurônio, muitos neurônios (dispostos em circuitos) estão

Psicopatologia Fenomenológica Contemporânea, 2017;6(2):81-92 
implicados em um comportamento singular, um gene pode afetar múltiplos neurônios, um neurônio pode estar implicado em muitos circuitos e comportamentos, e assim por diante, numa trama de crescente enredamento, que abarca fatores embriogenéticos, epigenéticos e ambientais (Schaffner, 2008). Ainda segundo este autor, que revisou cuidadosamente a literatura sobre a determinação do padrão alimentar do $C$. elegans, mesmo a elucidação da referida variação dicotômica do comportamento desse organismo tão simples e bem conhecido mostra que as reduções possíveis são apenas parciais e que é necessário que as explicações envolvam diferentes níveis de agregação e análise. O exemplo do autor relembra, em certa medida, a célebre assertiva de Georges Canguilhem (2002 [1943]), segundo a qual, "viver é, mesmo para uma ameba, preferir e excluir".

Outro aspecto a ser salientado é que, a despeito do forte apelo exercido por explicações etiológicas ou causais (e existem ótimas razões históricas na medicina que justificam seu elevado status), nem sempre uma explicação etiológica ou causal é a mais relevante ou útil para todo e qualquer propósito (Schaffner, 2002). Muitas vezes, variáveis clínicas têm maior utilidade e valor preditivo, inclusive para o planejamento terapêutico.

As observações anteriores apoiam a ideia - ainda que partindo do caso emblemático de um nematoide - de que a adoção de modelos multinível faria mais justiça à realidade das manifestações psicopatológicas ${ }^{2}$. Nestes modelos, coexistem múltiplos níveis de agregação das entidades e de análise, que guardam entre si complexas relações de influência recíproca. Assim, admite-se que ocorra uma causalidade bidirecional entre os múltiplos níveis e o vetor causal atuaria tanto no sentido top-down, como no bottom-up. E, mais importante, não haveria, desse modo, um nível fundamental ou uma hierarquia fixa e preestabelecida entre os níveis, embora,

\footnotetext{
${ }^{2}$ É preciso ressaltar, contudo, que admitir a complexidade causal não implica, necessariamente, na adoção de modelos multinível, pois existem modelos alternativos para dar conta de redes causais complexas. Para mencionar apenas dois exemplos, existem as abordagens sofisticadas de Mackie (1965 e 1974) e de Campbell (2008). Mackie, em sua análise INUS (acrônimo para insufficient but nonredundant part of an unnecessary but sufficient condition) oferece um modelo dinâmico, que admite a existência de influências causais fracas e inespecíficas atuando em conjunto e que permitiria generalizações incompletas e probabilísticas. Campbell, recusando a demanda por inteligibilidade, que estaria na base do apelo dos modelos multinível, propõe o reconhecimento de uma causalidade múltipla (many-sorted or multisorted), com variáveis de diferentes tipos, com ênfase em uma abordagem intervencionista. Isto é, para esse autor, não é necessário que os elementos causais estejam organizados de forma inteligível, basta que cada um deles tenha seu papel causal estabelecido.
}

Psicopatologia Fenomenológica Contemporânea, 2017;6(2):81-92 
evidentemente, a relevância relativa de cada nível seja desigual nos diferentes casos - mas isso é algo que só se determinaria a posteriori.

Diversos modelos multinível já foram propostos, na medicina geral e na psiquiatria, e alguns deles se tornaram bem conhecidos. O modelo biopsicossocial de Engel (1980) alcançou, inclusive, grande notoriedade, mas, na prática, pouco contribuiu para produzir e refinar nossa concepção de causalidade e para aprofundar o entendimento dos processos causais complexos das doenças. Décadas após sua proposição, o modelo biopsicossocial parece ter funcionado mais como um artifício retórico de grande poder generalizante e pouca especificidade, do que como um verdadeiro dispositivo heurístico. McHugh e Slavney (1998) foram mais específicos e procuraram capturar as bases e métodos da prática psiquiátrica em seu modelo de perspectivas múltiplas (doenças, dimensões da personalidade, comportamentos e histórias de vida). As diferentes perspectivas poderiam ser consideradas simultaneamente, com importância relativa caso a caso, momento a momento. Tal modelo faz justiça ao cenário clínico cotidiano, mas também não contribui muito para esclarecer como se daria o complexo interjogo de fatores de natureza diversa, que intervém na causação dos transtornos mentais. Kendler (2005), alinhandose aos autores mencionados neste parágrafo, também defende o pluralismo explicativo. Para Kendler, o desafio é encontrar, para cada tipo de fenômeno, o nível mais apropriado de explicação, isto é, um nível que não seja nem básico demais, nem abstrato demais. Segundo sua acepção, o nível adequado seria aquele que permitisse as implicações mais úteis em matéria de informação e, em termos de operação no mundo, maior eficiência ${ }^{3}$.

Três exemplos são fornecidos por Kendler (2005) para ilustrar a ideia de nível adequado de análise: 1) o de uma fisiologista que estuda a regulação hormonal e que examina grandes moléculas: embora as moléculas sejam constituídas por átomos, os quais, por sua vez, são compostos por partículas subatômicas, a física de partículas não é a melhor alternativa para explicar o comportamento dos receptores hormonais ${ }^{4}$; 2) o de uma análise estatística

\footnotetext{
${ }^{3}$ Eficiência para propósitos específicos, cuja escolha, naturalmente, sempre envolve valores.

${ }^{4}$ Pelo menos no estágio atual do desenvolvimento dessas disciplinas científicas. É concebível que novas interfaces físico-químicas sejam desenvolvidas e que o comportamento de partículas se torne relevante para o entendimento do comportamento das moléculas. As fronteiras entre os níveis seriam mutáveis, como o próprio conhecimento.
} 
malsucedida por erro de programação (software), que não pode ser consertada por um reparo nos circuitos do computador utilizado (hardware); 3) o de uma mãe que, inconformada com uma decisão do filho, que ela considera seriamente equivocada, considera que deve haver algo errado em seu cérebro e pede a uma psiquiatra que faça uma ressonância magnética.

Na clínica psiquiátrica cotidiana, entretanto, é preciso julgar, a cada momento, o que é relevante e qual é o melhor plano explicativo, para abordá-lo. Em outras palavras, haveria uma radical indeterminação inicial do foco de atenção. $\mathrm{Na}$ medida em que o encontro clínico acontece, mudanças de perspectiva e de níveis explicativos se sucedem e se alternam, ocorrendo tanto um processo de "zooming in", em que o cérebro, ou mesmo os genes, são alçados a uma posição de primazia, quanto um processo de "zooming out", em que a vida relacional, ou mesmo a situação social, recebem precedência. O clínico experiente, que combina conhecimento teórico ("know that") e habilidade ("know how"), faz essas transições de forma bastante natural e quase imperceptível. É como se, a cada momento, algo se impusesse a ele como o mais relevante na situação.

A pergunta central deste artigo, portanto, é se tais mudanças de perspectiva e de níveis explicativos, que acontecem o tempo todo na clínica psiquiátrica (comandadas pela combinação entre conhecimento teórico e conhecimento prático, que define a expertise), podem ser inteiramente codificadas, isto é, se seria possível capturar integralmente, em regras ou algoritmos, o complexo interjogo entre os determinantes dessas hierarquias transitórias e cambiantes.

De acordo com o cientista e filósofo Michael Polanyi (2009[1966]), que salienta a dimensão tácita do conhecimento, "we can know more than we can tell", o reconhecimento de fisionomias seria um bom exemplo disso: identificamos uma pessoa dentre inúmeras outras (por mais semelhantes que sejam), sem que saibamos exatamente a que características atribuímos tal diferenciação. Apreendemos, simultaneamente, a parte e o todo, numa dada configuração (Gestalt), de uma forma bastante difícil de ser explicada. Fazemos isso com competência e desempenhamos muito melhor a tarefa em si, do que conseguimos explicar as razões do nosso êxito. Polanyi (2009[1966]) também ressalta a profunda interdependência entre o conhecimento teórico ("know that") e o conhecimento prático ("know how"): "These two aspects of knowing

Psicopatologia Fenomenológica Contemporânea, 2017;6(2):81-92 
have a similar structure and neither is ever present without the other. This is particularly clear in the art of diagnosing, which intimately combines skillful testing with expert observation."

Para Polanyi (2009[1966]), o ideal perseguido pela ciência de um conhecimento objetivo e independente (isto é, apartado de quaisquer pontos de vista e interesses), com a eliminação de todos os elementos pessoais do conhecimento, é, não apenas inalcançável, mas radicalmente contraproducente: "the process of formalizing all knowledge to the exclusion of any tacit knowing is self-defeating". Isto porque o conhecimento tácito desempenharia um papel fundamental na própria identificação e delimitação de um problema científico, na consideração do tipo de abordagem que seria adequada para sua investigação e, finalmente, na antecipação do que contaria como uma solução válida para o problema em questão.

Ainda de acordo com Polanyi (2009[1966]), no caso de sistemas complexos, que possuem múltiplos níveis de organização, cada nível seria regulado por suas próprias regras, mas também pelo que ocorre na estrutura como um todo. Em outros termos, estamos lidando aqui com o fenômeno da emergência e, segundo esse autor, aquilo que emerge em um nível mais alto não pode ser plenamente explicado pelo nível mais baixo. Cada nível mais elevado adiciona uma nova camada de complexidade ao sistema (que não pode ser descrita na linguagem do nível mais baixo) e o transforma, como um todo. E essa entidade abrangente, composta pelo conjunto dos diferentes níveis, exerceria controle sobre cada um desses níveis.

O filósofo Tim Thornton (2006) propõe que o conhecimento tácito funcione como um verdadeiro fator de unificação entre a medicina baseada em evidências e o julgamento clínico. Mobilizando vasto arsenal filosófico (McDowell, Polanyi, Kuhn, Wittgenstein) e científico (Collins), Thornton destaca a importância crucial do conhecimento tácito, não apenas para a solução de problemas científicos ("puzzle solving"), mas também para tarefas aparentemente mais objetivas e potencialmente codificáveis, como no exemplo ilustrativo da (dificuldade de) replicação de um tipo específico de equipamento de laser em um laboratório de física aplicada, a partir de um conjunto de instruções. Thornton critica o preconceito de base de que todos os julgamentos genuinamente cognitivos devam ser governados por regras, de que a dedução estaria na raiz de toda concepção de racionalidade e, por conseguinte, de que princípios universais possam ser formulados. Afinal, e o autor citado recorre aqui ao célebre argumento de 
Wittgenstein sobre seguir regras: "whatever explicit guidelines can be drawn up to guide judgement the specification of what counts as correctly following them has to remain implicit" (Thornton, 2006).

O conto de Edgar Allan Poe, “Os crimes da Rua Morgue”, talvez lance luz sobre a noção de conhecimento tácito. Ao analisar as diferenças entre as habilidades requisitadas nos jogos de xadrez, dama e whist (jogo de cartas semelhante ao bridge), ele se dedica a compreender mais densamente o que é solicitado a um bom jogador de whist, argumentando que, embora tal jogo pressuponha habilidades, como atenção, memória, concentração e cálculo, ele exige ultrapassálas - a habilidade do analista, ou em nosso caso, e por analogia, do clínico, para além do quão válidas são suas observações e inferências, consistiria em saber $o$ que observar.

Enfim, o que este artigo sugere é que a psiquiatria precisa reconhecer e lidar com a complexidade, tanto no plano clínico, como em matéria de teoria e explicações causais; que a adoção de um reducionismo parcial, incompleto e gradual é aceitável e, mais que isso, desejável em inúmeros casos; que modelos multinível de explicação e intervenção mais sofisticados são necessários para fazer justiça à complexidade dos fenômenos psicopatológicos e aos desafios terapêuticos; que toda codificação tem limitações; e, finalmente, que se deve afirmar a centralidade do julgamento clínico em psiquiatria. Julgamento este que é plenamente racional (posto que baseado e/ou constrangido por conceitos), a despeito de ser não dedutivamente fundamentado, contendo elementos tácitos irredutíveis e de grande relevância ao raciocínio clínico. 


\section{Referências}

Andreasen, N. C. (1995). Posttraumatic stress disorder: psychology, biology, and the Manichaean warfare between false dichotomies. American Journal of Psychiatry, 152(7), 963-965.

Berrios, G. E., \& Chen, E.Y.H. (1993). Recognising psychiatric symptoms: relevance to the diagnostic process. British Journal of Psychiatry, 163, 308-314.

Campbell, J. (2008). Causation in Psychiatry. In: Kenneth S. Kendler\& Josef Parnas (eds.) Philosophical Issues in Psychiatry. Baltimore, Maryland: Johns Hopkins University Press. Canguilhem, G. (2002) [1943]. O normal e o patológico. Rio de Janeiro: Forense Universitária.

Engel. G. L. (1980). The clinical application of the biopsychosocial model. American Journal of Psychiatry, 137(5), 535-544.

Fleck, L. (1979) [1935]. Genesis and development of a scientific fact. Chicago: University of Chicago Press.

Kendler, K. S. (2005). Toward a Philosophical Structure for Psychiatry. American Journal of Psychiatry, 162(3), 433-440.

Mackie, J. L. (1965). Causes and conditions. American Philosophical Quarterly, 2(4), 245-64.

Mackie, J. L. (1974). The Cement of the Universe. Oxford: Clarendon Press.

McHugh, P. R., \& Slavney, P. R. (1998). The Perspectives of Psychiatry. Baltimore, Maryland: Johns Hopkins University Press.

Miller, G. A., \& Keller, J. (2000). Psychology and Neuroscience: Making Peace. Current Directions in Psychological Science, 9(6), 212-215.doi: 10.1111/1467-8721.00097

National Institute of Mental Health (NIMH). StrategicPlan. (2008). Recuperado em 12/02/2014 de <http://www.nimh.nih.gov/about/strategic-planning-reports/nimh-strategic-plan2008.pdf>.

Nagel, T. (1986). The view from nowhere. New York: Oxford University Press.

Poe, E. A. (1992) [1841].The murders in the Rue Morgue. In: Complete Tales \& Poems.New York: Barnes \& Noble Books.

Polanyi, M. (2009) [1966]. The Tacit Dimension. Chicago: The University of Chicago Press. 
Schaffner, K. F. (2002). Clinical and Etiological Psychiatric Diagnoses: Do Causes Count? In: John Z. Sadler (ed.). Descriptions and Prescriptions - Values, Mental Disorders, and the DSMs. Baltimore, Maryland: The Johns Hopkins University Press.

Schaffner, K. F. (2008). Etiological Models in Psychiatry: Reductive and Nonreductive Approaches. In: Kenneth S. Kendler\& Josef Parnas (eds.). Philosophical Issues in Psychiatry. Baltimore, Maryland: Johns Hopkins University Press.

Thornton, T. (2006). Tacit knowledge as the unifying factor in evidence based medicine and clinical judgement. Philosophy, Ethics, and Humanities in Medicine, 1:2.doi:10.1186/1747$5341-1-2$

Zorzanelli, R., Dalgalarrondo, P. \& Banzato, C.E.M. (2016). Realismo e pragmatismo em psiquiatria: um debate. Revista Latinoamericana de Psicopatologia Fundamental, 19(3), 527543. doi: 10.1590/1415-4714.2016v19n3p527.11 